\title{
Dinâmica organizacional, crescimento das consultorias e mudanças nos conteúdos gerenciais nos anos 90
}

\author{
Júlio Cesar Donadone \\ Doutor pelo Departamento de Engenharia de Produção da Escola Politécnica \\ da Universidade de São Paulo e professor do Departamento de Engenharia \\ de Produção da Escola da Engenharia da Universidade Federal de São Carlos.
}

LaERTE IDAL SzNeLwar

Professor do Departamento de Engenharia de Produção da Escola Politécnica da Universidade de São Paulo.

\begin{abstract}
Resumo
A partir dos anos noventa a figura do consultor se tornou cada vez mais presente no dia-a-dia das empresas. Neste artigo procura-se discutir o crescimento do mercado de consultorias e as mudanças nos conteúdos das funções gerenciais decorrentes das transformações no controle e na propriedade das empresas nos anos 90 . Para tanto utilizam-se os seguintes pontos de referência: ij Primeiro, a dinâmica organizacional das últimas décadas, em especial as formulações que procuram lidar com a questão da influência do campo financeiro nas formas de gestão e nos conteúdos gerenciais das empresas, em especial neste estudo os processos de fusão, Take Over e privatização da década de 1990. ii) Num segundo momento, enfoco o mercado de consultoria internacional, procurando identificar suas características e principais mudanças nas últimas décadas. Desta maneira, busca-se caracterizar o relacionamento entre as firmas de consultoria e as demais organizações, que se constitui como um importante elemento para o entendimento da dinâmica organizacional do período e dos novos formatos das carreiras e funções gerenciais.
\end{abstract}

Palavras-chave

Consultoria, gerentes, mudanças organizacionais.

\section{Organizational dynamics, consulting market's growth process and the changes in the managerial work's subject in the 90's}

\begin{abstract}
This article intends to contribute toward a better understanding of the consulting market's growth process, its forms of action and relationship of consulting firms with other organizations, based on points of reference used in this research. The article begins focusing on the market of international consulting firms, seeking to identify its main characteristics and changes in the recent decades. This is followed by an analysis based on the organizational dynamics of the last decades, especially on the formulations that attempt to work with the subject of the influence of the financial field in the administration forms and in the managerial contents of the companies. Using these two approaches the article seeks to characterize the relationship between the consulting firms and other organizations and to supply an important element for the understanding the development of organizational choices in companies and the forms of manager' work.
\end{abstract}

Key words

Management, consulting firms, organizational changes. 
INVESTIDORES INSTITUCIONAIS E A DINÂMICA ORGANIZACIONAL NOS ANOS 90

Para que se possa entender o crescimento e a importância que as consultorias ganham a partir da década de 1990 e sua influência nos atributos gerenciais, recorre-se a formulações sobre a mudança por que passavam as empresas no período e suas interdependências no desenvolvimento do campo de consultoria. Em especial, neste trabalho, enfatiza-se o processo pelo qual o entendimento e as representações acerca do mundo organizacional foram sendo colonizados pela lógica financeira, mais explicitamente, como ocorre a mudança na governança corporativa com a atuação de grandes investidores institucionais, representados por fundos de pensão, companhias de seguros e fundos de investimento, a partir dos anos oitenta nos Estados Unidos. A escolha deve-se ao país apresentar-se como o principal pólo de influência e desenvolvimento histórico do setor, sede das empresas líderes e o maior mercado mundial. Centraliza-se a análise na disputa entre gerentes e os investidores institucionais sobre o controle das grandes empresas americanas, que serviu de suporte para a maioria dos processos de reestruturação que ocorreram durante os anos oitenta e noventa.

Para compreender e posicionar os contendores é preciso voltar ao início do século vinte e à chamada "Revolução dos Gerentes" americanos. Como discutido por Chandeler (1990), o desenvolvimento das empresas, focado no ganho de escala, e o conseqüente aumento da complexidade das organizações, fez com que as decisões sobre aspectos de produção, distribuição e dimensionamento dos recursos necessários fossem alocadas às pessoas dedicadas em tempo integral e que recebiam salários: os gerentes profissionais. $\mathrm{O}$ aumento da concorrência e as estratégias de diversificação das empresas vieram a corroborar ainda mais o desenvolvimento do espaço gerencial. No período, um número crescente de empresas transformava-se em holding, designando gerentes responsáveis por cada uma das firmas componentes da empresa. O formato reforçava ainda mais a posição dos gerentes no controle das grandes empresas, uma vez que o conselho diretor do holding tinha sua maioria composta pelos principais executivos de cada unidade. Tais acontecimentos fizeram com que, paulatinamente, o controle das empresas passasse dos proprietários e, em muitos casos, fundadores das empresas para as mãos de gerentes profissionais na maioria da empresas americanas. Como referência, pode-se indicar que, em 1974, 82\% das maiores firmas não-financeiras estavam sob o controle de gerentes, contra apenas 40\% em 1929. (CHANDELER, 1990).
Desde o final da Segunda Guerra Mundial, o corpo de gerentes profissionais e as estruturas por departamento tinham ganhado importância, sendo apresentados como um dos fatores responsáveis pelo sucesso do capitalismo profissionalizado. Era a consolidação da "Revolução dos Gerentes": a substituição, nos cargos gerenciais, de pessoas ligadas aos donos das empresas e de pessoas que aprenderam no local de trabalho, por profissionais que tinham formação específica para exercer as funções gerenciais e que se tornaram "indispensáveis" para o bom funcionamento da empresa.

Na década de 1980, começava a ser questionado o valor intrinsecamente positivo do corpo gerencial. Ele começava a ter questionado o seu papel de indispensável para o funcionamento da empresa, sendo introduzidos conceitos como o "downsizing", que colocava a necessidade de reformulação dos modelos tradicionais da organização da empresa. Nesse processo de reestruturação, as gerências intermediárias passaram a ser vistas como responsáveis pela morosidade no processo de comunicação das empresas, por sua apropriação de parte considerável dos dividendos dos acionistas, através de salários desnecessariamente altos, benefícios correlatos e adoção de estratégias empresariais que privilegiavam a sua estabilidade no emprego, ao invés da maximização do lucro do acionista; e também eram questionados os "agora" elevados custos para sua manutenção. Tais formulações encontravam respaldo nas formulações teóricas da "Teoria da Agência" (FAMA,1980). A base desse corpo teórico é modelo de principal-agente, que enfatiza que uma característica comum das transações econômicas é que indivíduos (principais) contratam outros (agentes) para realizar algum serviço. O problema é que nem sempre os interesses dos dois coincidem, e o principal precisa estabelecer formas de incentivos e monitoramento sobre o agente para assegurar que ele haja de acordo como seus interesses. No contexto organizacional, o modelo é aplicado para explicar as relações entre proprietários, muitas vezes os detentores das ações, e os gerentes.

Um fator que vem nos dar auxílio no entendimento das mudanças nas empresas no final do século XX é a questão do surgimento e fortalecimento dos investidores institucionais a partir da década de 1970. Durante os anos oitenta o debate sobre propriedade e gerenciamento da empresa ganha um agente: os investidores institucionais. A transferência de ações de proprietários individuais para instituições, como fundos de pensão e de investimento e companhias de seguros, tornou possíveis os processos de take over, ou seja, de assumir a direção de empresas nas quais esses investidores possuíam ações, e trouxe novos contornos que redirecionaram os questio- 
namentos acerca da função e da importância dos gerentes nas empresas. Os investidores institucionais expandiram sua parcela das ações das empresas, sendo que, em 1965, as ações possuídas por proprietários individuais representavam $84 \%$ do total de ações das companhias e os investidores institucionais apenas 16\%. Em 1990 a fração de investidores individuais tinha caído para $54 \%$ e a fração institucional subira para $46 \%$ (USEEM, 1996)

Durante os anos 1950, a maioria das ações das companhias estava nas mãos de investidores individuais. A era dos órfãos e viúvas era o período onde um grande número de pequenos acionistas financiava as companhias com o objetivo de preservar suas poupanças para o futuro, através dos dividendos recebidos. Em 1950, $90 \%$ das ações das companhias americanas tinham como proprietários esses tipo de investidor (USEEM, 1996).

A partir dos anos setenta, o quadro começa a se alterar com o fortalecimento dos investidores institucionais. Durante os anos cinqüenta e sessenta havia uma série de restrições para que empresas de seguro e fundos de pensão pudessem inserir ações de companhias nos seus portfólios, enquanto os fundos de investimentos ainda ocupam um pequeno espaço no mercado de ações. Entretanto, nos anos setenta, modificações viriam dar suporte à atuação dos investidores institucionais. A primeira mudança estava relacionada às mudanças na legislação, que permitia aos fundos de pensão e às companhias de seguro investir proporções consideráveis de seus portfolios em ações de companhias. Tal posicionamento desses investidores era fortemente influenciado pelo período inflacionário, que levava os fundos a buscar novas formas de ganhos para compensar seus investidores (FLIGSTEIN,1993). Outra mudança do período foi o fim da diferenciação quanto às possibilidades de investimento do dinheiro aplicado entre bancos comerciais e de poupança, o que fez com que investidores de longo prazo buscassem rentabilidades compatíveis com outras aplicações financeiras mais rentáveis, como as operações de curto prazo.

Nos anos oitenta os investidores institucionais passam a ocupar uma posição mais ativa quanto ao gerenciamento das empresas, ainda em muitos casos subordinado aos interesses gerencias. Mas aos poucos crescia a pressão por mudanças que proporcionassem um maior controle das empresas e maior retorno aos investidores. Começavam a ficar mais evidentes os "shareholder rigths" e a acirrar-se a disputa entre investidores e gerentes das corporações.

A atuação dos investidores institucionais também encontrava respaldo no crescimento do movimento de fusões de aquisições. De certa forma, os dois processos se realimentavam. De um lado, a difusão das práticas corporativas associadas à lógica financeira; de outro, a tomada de posições e os primeiros movimentos por meio de take over dos investidores institucionais. Os valores negociados nos processos de fusão e incorporação cresceram de US\$ 44,3 bilhões em 1980 para US\$ 246 bilhões em 1988. Para Fligstein; Markowitz (1990), as políticas antitruste mais moderadas e o corte de impostos na era Reagan forneceram incentivo e dinheiro que servirão de suporte para o crescimento das fusões e incorporações no período.

Entretanto, onde emergia de forma mais significativa o poder dos proprietários versus os gerentes era na questão da transformação de empresas de capital aberto, com ações negociadas na bolsa, em empresas pertencentes a um determinado grupo de investidores. Isso ocorria por meio da compra (buyoff) das parcelas majoritárias das ações das empresas e, por conseguinte, o controle das mesmas. O comprador passava a ser o novo dono das empresas. No início, os processos se concentravam nas pequenas ou médias firmas com transações envolvendo valores, em 1986, de US\$ 281 milhões e, em 1987, de US\$ 469 milhões, o que atingia uma parcela quase insignificante das 500 maiores empresas americanas ( FLIGSTEIN; MARKOWITZ 1990).

Contudo, os buyoff da Borg Warner, de US\$ 3,8 bilhões, e da Beatrice Companhies, de US\$ 5,4 bilhões, começavam a indicar que a atuação dos investidores institucionais entrava em novo estágio da disputa pelo controle das grandes empresas. Seus movimentos passavam a ser mais incisivos, passando de arranjos conjuntos, como os executivos das empresas para take over hostile/ buyoff, ou seja, a tomada da empresa e sua propriedade por um grupo de investidores por meio de arranjos entre grupos de investidores que permitissem o controle acionário da mesma. Das 500 maiores empresas industriais listadas na Fortune, em 1980, 143 foram alvos de take over ou buyoff até o final da década e um terço das empresas de capital aberto deixaram de existir como tais.

Se nos anos oitenta os investidores institucionais ganham destaque e acumulam parcela significativa das ações das grandes empresas americanas, nos anos noventa todo esse arsenal é utilizado na disputa com os gerentes sobre o controle das corporações. As pressões dos novos donos das empresas têm conseqüência no desenho organizacional e na composição de poder nas empresas.

As mudanças na composição do poder das empresas se davam em duas frentes. A primeira, por meio de medidas que derrubassem barreiras que pudessem impedi-los de exercer sua influência nos rumos da firma, favorecessem os quadros diretivos ou dificultassem aos investidores assumir a direção das empresas por meio de arranjos de acionistas (take over). Como exemplo, tem-se a crescen- 
te retirada das Poison Pills como instrumento de gestão das empresas. Segundo tal mecanismo, quando o conselho diretor da empresas rejeitasse a oferta de mudança no controle da firma mas, ainda assim, o proponente adquiria-o por meio da compra de ações, era garantido aos acionistas o direito de comprar com desconto as ações da empresa, ou do agente que adquiriu o controle acionário da empresa, desencorajando as possíveis tentativas. $\mathrm{Na}$ outra frente, pela ampliação do poder dos investidores institucionais nos conselhos diretores das empresas, como a criação de cargos na alta gerência com o intuito de monitorar as ações dos executivos da empresa e atender aos interesses específicos dos investidores institucionais.

Quanto à reorganização das empresas, os investidores, ao assumir as empresas, buscaram enfatizar a descentralização da responsabilidade da administração e dos resultados. As unidades deveriam ser encaradas como negócios autônomos, sendo avaliadas pelos resultados financeiros que pudessem obter em comparação a outras possibilidades de investimento. Neste sentido, recorria-se à "agência" do negócio, buscando minimizar os possíveis desvios de interesse originários dos vários níveis gerenciais. Como consequiências tem-se a busca pelo "Core Business" da empresa no qual o retorno dos investimentos dos acionistas tinha a maior chance de ser maximizado; como também, em muitos casos, a redução de grandes contingentes de empregados, que era visualizada como uma maneira de redução dos custos e, por conseqüência, de aumento do retorno dos investimentos de determinada empresa ou unidade. Como discutido por Useem (1993), a questão da demissão estava mais relacionada à tentativa dos gerentes em mostrar que estavam gerando os lucros esperados do que uma imposição direta dos investidores.
Os processos de fusão e incorporação nas empresas americanas se intensificam nos anos noventa, passando de 2.793 operações em 1993 para 3.478 em 1995. O volume financeiro aumenta de US\$ 277 bilhões em 1993 para US\$ 660 bilhões em 1996. Dentre as transações da década é possível indicar algumas que estão entre as maiores fusões e aquisições ocorridas no mundo, como por exemplo: entre a Exxon e a Mobil, de US\$ 86,3 bilhões em 1998; o Travelers Group e o Citibank (US\$ 72 bilhões); entre a AT\&T e a TeleCom (US\$ 70 bilhões).

\section{A dinâmica organizacional brasileira: as privatizações, fusões e incorporações.}

Para compreender a dinâmica organizacional brasileira nas últimas décadas, é necessário remeter-se aos processos de privatizações, em especial aos acontecimentos dos anos noventa. A transferência para setores privados de grandes empresas estatais foi um importante fator de mudança nos arranjos organizacionais do período, tanto pelo processo de fusões e incorporações associadas à privatização, quanto pelo surgimento e fortalecimento de agentes como os fundos de pensão e bancos, bem como a crescente presença de investidores internacionais.

As privatizações também influenciaram de modo decisivo o movimento de fusões e incorporações por que passavam as empresas brasileiras na década de noventa. Isso se deu, primeiramente, com a transferência para o setor privado das empresas de siderurgia e petroquímica no início da década. Posteriormente, com a privatização dos serviços públicos, o movimento de fusões e incorporações ganha uma nova dinâmica, tanto no número de transações quanto na composição acionária das empresas, com a crescente entrada de investidores estrangeiros.

Quadro 1: 0 poder dos investidores institucionais nos anos 90.

\begin{tabular}{|c|c|c|c|}
\hline $\begin{array}{l}\text { O tamanho dos } \\
\text { investidores } \\
\text { institucionais }\end{array}$ & $\begin{array}{l}500 \text { bilhões de } \\
\text { dólares em ativos de } \\
\text { empresas }\end{array}$ & $\begin{array}{l}\text { 2.226 trilhões de } \\
\text { dólares em } \\
\text { depósitos }\end{array}$ & \\
\hline $\begin{array}{l}\text { ações negociadas } \\
\text { movimentadas por } \\
\text { investidores em blocos de } \\
10.000 \text { ou mais }\end{array}$ & $\begin{array}{l}\text { em } 1965 \\
3 \%\end{array}$ & $\begin{array}{l}\text { Anos } 80 \\
>50 \%\end{array}$ & \\
\hline $\begin{array}{l}\text { Em } 1990 \\
\text { Maioria das ações em mais } \\
\text { de } 50 \% \text { do ranking das } \\
1.000 \text { maiores companhias } \\
\text { americanas. }\end{array}$ & $\begin{array}{l}\text { 59\% das ações } \\
\text { Johnson \& Johnson }\end{array}$ & $\begin{array}{l}\text { 83\% das ações } \\
\text { Intel }\end{array}$ & $\begin{array}{l}\text { 52\% das ações } \\
\text { General Electric }\end{array}$ \\
\hline
\end{tabular}

Fonte: Useem (1996). 
No final dos anos noventa, investidores privados controlavam os setores de telecomunicações e ferrovias, os maiores portos do País, algumas de suas principais rodovias, dois terços da distribuição de eletricidade e uma grande parte da geração de energia elétrica.

O processo de privatização também trouxe novos elementos para o entendimento das formas de controle acionário das empresas brasileiras, por meio da crescente presença de fundos de pensão, de bancos, o que inclui instituições financeiras, fundos de investimentos e bancos de investimentos, e posse de ações por funcionários das empresas. Como, por exemplo, no setor petroquímico, onde os fundos de pensão representam $11,2 \%$, os bancos $24,2 \%$ e os funcionários $7,4 \%$; no setor siderúrgico, $30,3 \%$ bancos, 24,9\% fundos de pensão e 13,2\% os funcionários. Siffert Filho; Souza e Silva (1990), a partir dos dados mostrados anteriormente, afirmam que, no caso brasileiro, "entre as características mais marcantes do processo de mudança das empresas nos anos noventa podem ser ressaltados dois aspectos: a expansão do padrão de controle societário, com base no compartilhamento do controle entre sócios nacionais e estrangeiros, e a formação de alianças estratégicas entre grupos nacionais e internacionais".

No período há a expansão do controle compartilhado das grandes corporações no Brasil, passando de 5 para 23 empresas entre as 100 maiores na década de noventa. Nesta forma de controle, nenhum sócio, de forma isolada, é majoritário, de modo que a gestão da empresa depende necessariamente de um acordo entre sócios controladores.

Para Siffert Filho; Souza e Silva (1990), as empresas privatizadas passaram, em sua grande maioria, a um controle compartilhado no qual estão presentes fundos de pensão, empresas nacionais e investidores estrangeiros. A participação deste tipo de controle, entre as 100 maiores empresas, atinge $18 \%$ em 1998. Tal arranjo de controle acionário representaria um novo tipo de controle societário para o conjunto das maiores empresas brasileiras e teria surgido como decorrência da privatização. De acordo com suas formulações: "Há, sobretudo, uma profunda reconfiguração dos principais atores e a formas com que passam a atuar. A saída do Estado de importantes setores do aparelho produtivo, a exemplo dos setores siderúrgico, petroquímico, de ferrovias, de energia etc., implicou um redesenho do tripé clássico que deu sustentação ao desenvolvimento nacional até os anos 80 , ou seja, o capital privado nacional, o capital estrangeiro e o capital estatal. Com a retirada deste, os dois primeiros se rearticularam. Nesse sentido, o processo de privatização foi o ponto de partida de movimentos de reestruturação societária e produtiva em vários setores".

Mello (1999) parece nos fornecer pistas importantes para o entendimento dessas mudanças na forma de controle acionário com as privatizações, ao indicar que a legislação brasileira permite uma divisão de um terço/dois terços entre ações com e sem direito a voto. Portanto, não estimulando a presença de pequenos acionistas, mas proporcionando que o controle possa ser garantido com a propriedade de apenas um sexto do capital. Entretanto, tal característica de um controle com participação acionária limitada estimula a criação de joint venture, fusões e aquisições, facilita a criação de grandes holdings e fortalece a posição de investidores institucionais nas privatizações. Isso parece evidente ao observar-se que $50 \%$ das empresas que apresentam controle compartilhado possuem sócios estrangeiros com participação significativa. Cabe ressaltar, também, que o crescimento da participação de grupos estrangeiros entre as maiores empresas se deu, em sua grande maioria, por intermédio de movimentos de fusões e aquisições e pela sua presença em diversos consórcios, seja na área de energia ou de telecomunicações.

\section{Gráfico 1: Participação das privatizações nas fusões e aquisições [US\$ milhões]}

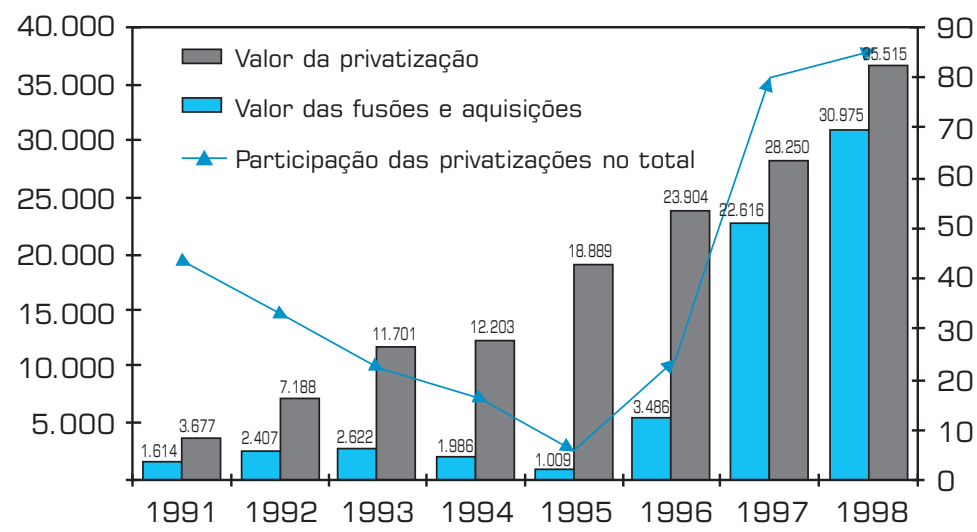

Fonte: BNDES, apud Siffert Filho \& Souza e Silva (1990). 
Gráfico 2: Evolução do número de fusões e aquisições no Brasil entre 1994 e 2000.

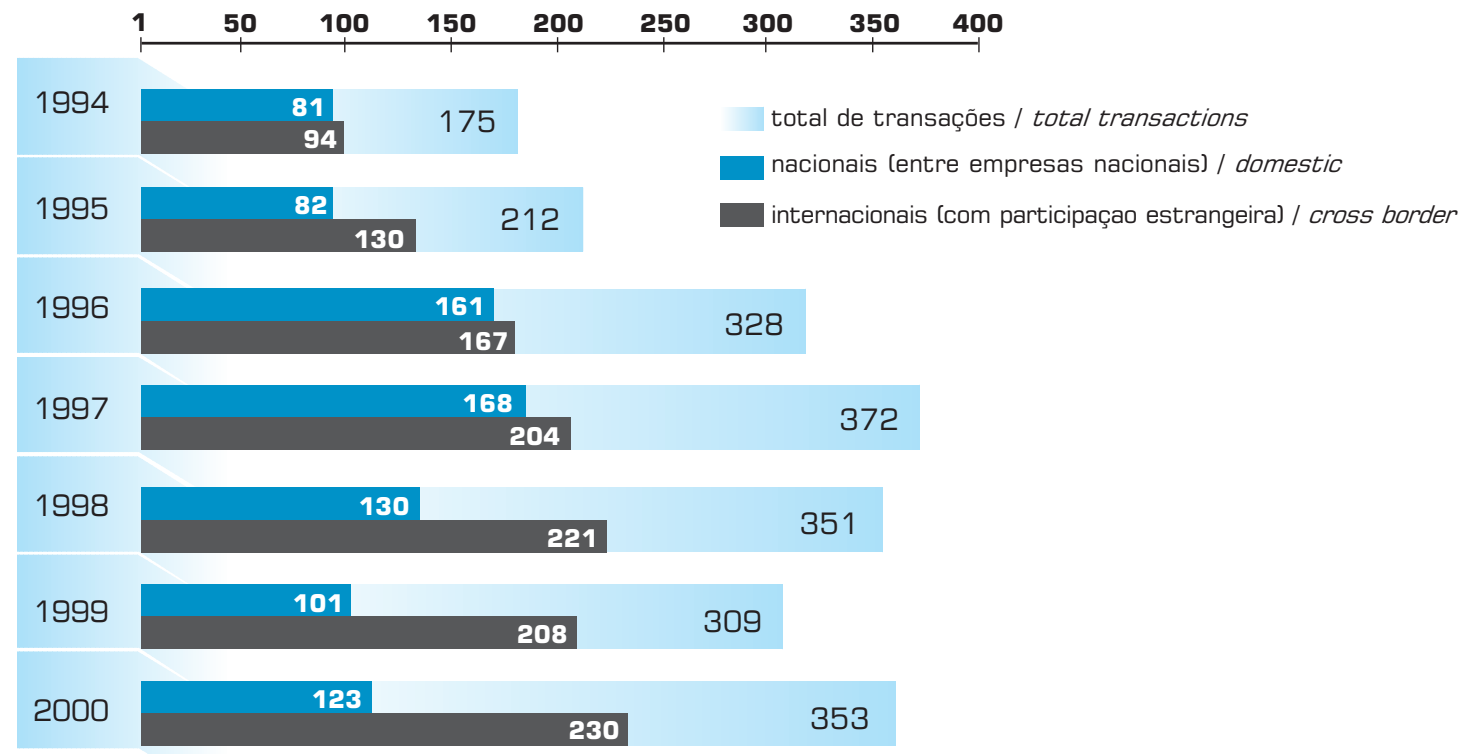

Fonte: KPMG

\section{A configuração do mercado de consultoria nas últimas décadas}

Os anos oitenta marcam o início de importantes transformações no mercado de consultoria organizacional. O crescimento e maior vislumbre do setor, associados a mudanças nas formas de atuação, de relacionamento com as empresas contratantes e inserção nos mercados de divulgação e venda de pacotes gerenciais, formataram características que serviram de suporte para a configuração e importância que o setor adquiriria nos anos noventa. Os dados apresentados e as análises sobre o mercado de consultoria foram desenvolvidos durante minha estadia como pesquisador visitante, sob a orientação do Professor Robert Cole, do Haas School of Business, da Universidade da Califórnia, sendo parte do meu doutorado (DONADONE, 2002).

No período destacava-se a implementação de ferramentas gerenciais inspiradas nas idéias de gestão empresarial japonesa. Tais ferramentas, respaldadas pela divulgação do sucesso das indústrias japonesas, em especial no que diz respeito à conquista de consideráveis parcelas do mercado norte-americano de automóveis, apareciam como uma referência para as empresas.

As tentativas de recontextualização das práticas japonesas serviam de um fértil terreno para a expansão das consultorias. Abriam-se novas frentes de atuação. Num primeiro momento, com as tentativas de interpretação e introdução de elementos das práticas gerenciais japonesas nas empresas ocidentais, sendo emblemática a discussão e implantação dos Círculos de Controle de Qualidade (CCQs). Outro destaque do período e que fornecia novos campos de atuação era o crescente mercado de certificação sobre procedimentos de gestão e de processo produtivos, representados principalmente pelas normas ISO e posteriormente, nos anos seguintes, as suas versões específicas, como a QS do setor automobilístico americano.

Com o decorrer da década, os espaços de atuação das consultorias ganham novas dimensões, mudando o enfoque de características funcionais das práticas japonesas para pacotes gerenciais que visavam contemplar os diversos setores presentes nas empresas. Tal passagem se evidencia na semântica e abrangência das propostas que passam a enfocar "Filosofias da Qualidade" como o Kaizen, e principalmente pelos conteúdos atribuídos ao TQM (Total Quality Management).

Como discutido por Cole (1998) nos seus estudos sobre a constituição e dinâmica dos movimentos pela Qualidade nas empresas americanas, os consultores aparecem como os principais vetores de difusão e implantação das novas formas de gestão com inspiração japonesa. Segundo o autor, no decorrer dos anos oitenta ocorre um processo de institucionalização de diversos agentes e estâncias profissionais e governamentais que buscam formular os conteúdos atribuídos ao tema qualidade; e um acirramento na disputa pela divulgação e implantação relacionadas ao assunto. Tal formulação tem importância neste estudo por fornecer tanto indicações para os motivos do crescimento da utilização de consultores quanto para as estra- 
tégias de conquista de espaço de atuação das empresas de consultoria, nos anos noventa.

Outro componente que forneceu contribuições para o cenário no qual as consultorias passam a atuar a partir dos anos oitenta é a questão da Tecnologia de Informação (TI). Num primeiro momento, com as mudanças ocasionadas com a difusão dos computadores pessoais nas empresas e, posteriormente, com a introdução de "pacotes de gerenciamento" baseados na Tecnologia de Informação.

$\mathrm{O}$ incremento na informatização de aspectos administrativos e da produção, com o intuito de ganhos de produtividade, e a utilização de softwares voltados à gestão de aspectos organizacionais, como, por exemplo, o MRP, possibilitavam um importante mercado para as consultorias, e também serviram de base para transformações na segmentação e nas formas de atuação do pólo central das consultorias internacionais na década seguinte. Por exemplo, no suporte à introdução das questões relacionadas ao uso da internet como ferramenta empresarial e a atuação de empresas especializadas em softwares de gestão, como a SAP e a ORACLE.

O final dos anos oitenta também aposentaria um componente central para o entendimento das configurações e constituição do setor de consultorias atual: a criação da Andersen Consulting. A empresa foi criada em 1989 a partir de um processo de divisão de negócios da Arthur Andersen Co. A Andersen nasce como a maior empresa de consultoria do mundo, contando com um contingente de 21.400 empregados e receita de 1,6 bilhões de dólares no seu primeiro ano (DONADONE, 2002).

Sua criação trazia uma série de características que o mercado de consultoria assumiria nos anos noventa. Um primeiro elemento a se destacar: tem-se novas formas de composição entre consultores e auditores. Os primeiros passando de uma condição de inseridos em grandes empresas de auditoria e contabilidade para ocupar um espaço próprio. A estratégia baseada no desenvolvimento e implantação de tecnologia de informação veio a constituir uma nova etapa da polarização entre as Accounting Firms e as denominadas firmas de consultoria em estratégia, tão bem representadas pela Mckinsey.

Também merece evidência, no período, a movimentação incisiva das Accounting Firms, das quais a Arthur Andersen fazia parte, no intuito de ocupar de maneira mais efetiva o crescente mercado de consultorias. Além do exemplo da criação da Andersen Consulting, ocorre uma série de fusões entre grandes representantes do setor, visando um ganho de escala e uma maior atuação no mercado de consultorias.

A criação das empresas KPMG, Deloitte Touche e Ernst \& Young no final dos anos oitenta viria, conjuntamente com a presença da Price Waterhouse, da Arthur
Andersen e da Coopers \& Lybrand, formar as denominadas Big Six Accounting Firms. Tal formação constituiria importante pólo de influência nas formas de atuação e configuração do setor de consultorias nos anos noventa.

\section{0 crescimento nos anos 90}

Se nos anos oitenta ocorrem uma série de posicionamentos e eventos que dão suporte a novos espaços para a atuação das consultorias, nos anos noventa o setor ganha em destaque e importância nos meios gerenciais e empresariais. Destacam-se por suas taxas de crescimento na receita e no porte das empresas e pela exposição na mídia. As receitas passaram de US\$ 22 bilhões em 1990 para mais de US\$ 100 bilhões dez anos depois, e entre as dez maiores empresas, é comum encontrarmos um contingente de empregados que supera 50.000 consultores e a receita de cinco bilhões de dólares. Vale lembrar que a Andersen, que nasceu como a maior empresa de consultoria do mundo em 1989, contava com 21.600 empregado e um faturamento de US\$ 1,6 bilhão (DONADONE,2002).

Um primeiro componente que traz contribuições para o entendimento da dinâmica do período é a questão dos processos de reengenharia presentes a partir do início dos anos noventa. As mudanças organizacionais associadas aos redesenhos organizacionais, a partir do "core business" da empresa, contribuíram para ampliar o espaço das consultorias nos meios gerenciais e empresariais.

Isso não ocorria apenas como um aumento nas possibilidades da atuação, mas principalmente pelas características intrínsecas e as conseqüências da implantação da reengenharia. $\mathrm{O}$ processo de construção e divulgação apresentava características que contemplavam aspectos da dinâmica do setor de consultoria no período. Dentre eles, podem-se destacar as questões relacionadas às formas de interação entre empresas de consultoria, imprensa de negócios e setores acadêmicos, estes últimos representados principalmente pelas "business schools".

Um primeiro ponto a se destacar é a questão de "um homem, uma idéia, uma nova consultoria", explicitada nas discussões acerca de modismos e gurus gerenciais. Com a difusão do processo de redesenho organizacional, James Champy e Michael Hammer, considerados os pais da reengenharia, são guindados ao primeiro time dos gurus gerenciais internacionais. Suas idéias foram primeiramente expostas no artigo que Michael Hammer publicou, Reengineering Work: Don't automate, Obliterate, na Harvard Business Review, em 1990, e posteriormente, em 1993, transformadas no livro Reenginering the corporation, o qual alcançou a marca de 17 milhões de livros vendidos em todo o mundo, ou seja, a reengenharia tornou-se uma das mais influentes formas de gestão e, conjuntamente, modismo empresarial, das últimas décadas. 
Para compreender a relação entre gurus /modismos gerenciais e a dinâmica da consultoria é preciso lembrar que, durante a década de oitenta, são diversos os exemplos de agentes que se revezam na formulação e venda de "pacotes gerenciais": P. Crosby/Quality is Free; Porter, M. /Competitive Strategy; e Kanter, R. /The Change Masters. Assim, a difusão da reengenharia é ao mesmo tempo oriunda dessa forma de atuação no mercado de consultoria, como também forneceu respaldo a possíveis candidatos a esse tipo de consultoria.

A divulgação centrada em artigos, em revistas de renome, sobre gerenciamento, na publicação de um livro com a função de carro-chefe das idéias e, posteriormente, a transformação do autor em guru e best seller, tinha elementos que vinham de encontro à crescente atuação de professores, principalmente das "business schools", em consultorias especializadas e de pequeno porte, por exemplo. Para essas empresas, o sucesso do formato da reengenharia fornecia a possibilidade de alcançar o restrito mundo das consultorias, representado pelas Accounting Firms e as empresas de estratégia.

Mas não era apenas na maneira pela qual eram difundidos que os processos de reengenharia forneciam novos elementos para o entendimento do espaço de consultoria nos anos noventa. Uma das formulações mais centrais das idéias de reengenharia, o donwsizing, também veio a contribuir com elementos para caracterização e difusão das consultorias, com as mudanças organizacionais nas empresas. Representados pelo achatamento da pirâmide de posições, cortes de funções, em alguns casos de departamentos inteiros, e processos de terceirização, um contingente de gerentes que foi deslocado dos antigos empregos buscou nas consultorias uma maneira de reconversão, seja prestando serviços às antigas empresas, como consultores associados a alguma consultoria, ou formando novas empresas que buscavam fornecer orientação sobre assuntos específicos antes desenvolvidos no seu trabalho.

As construções e representações das empresas associadas à necessidade de uma pirâmide gerencial também tinham como conseqüência um aumento na competição interna pelos cargos gerenciais, o que muitas vezes levava os ocupantes de tais posições a buscar, nas idéias dos consultores, gurus e livros sobre novas formas de gestão que possibilitam valiosos pontos na disputa interna das empresas.

Para sintetizar e compreender as transformações e os posicionamentos dos agentes no espaço de consultoria internacional no período, que compreende a década de oitenta até a meados dos anos noventa, me direciono a duas questões.

A primeira questão nos remete ao tamanho que as empresas líderes do setor foram adquirindo, principalmente a partir do final dos anos oitenta. Por exemplo, a Andersen Consulting passou de 21.660 funcionários em 1990 para 45.000 em 1996. Seu faturamento também apresenta um crescimento significativo, atingindo a cifra de US \$ 5,3 bilhões em 1996 contra 1,6 de seis anos antes.

Para se compreender tal crescimento, é preciso lembrar da movimentação das Accounting Firms no intuito de ocupar o mercado de consultoria, com a criação da Andersen Consulting ou por fusões de empresas como a KPMG. Independentemente da forma, as seis grandes: KPMG, Deloitte Touche, Ernst \& Young, Price Waterhouse, Arthur Andersen e Coopers \& Lybrand, apresentam-se

\section{Gráfico 3: O Mercado mundial de consultorias nos anos noventa.}

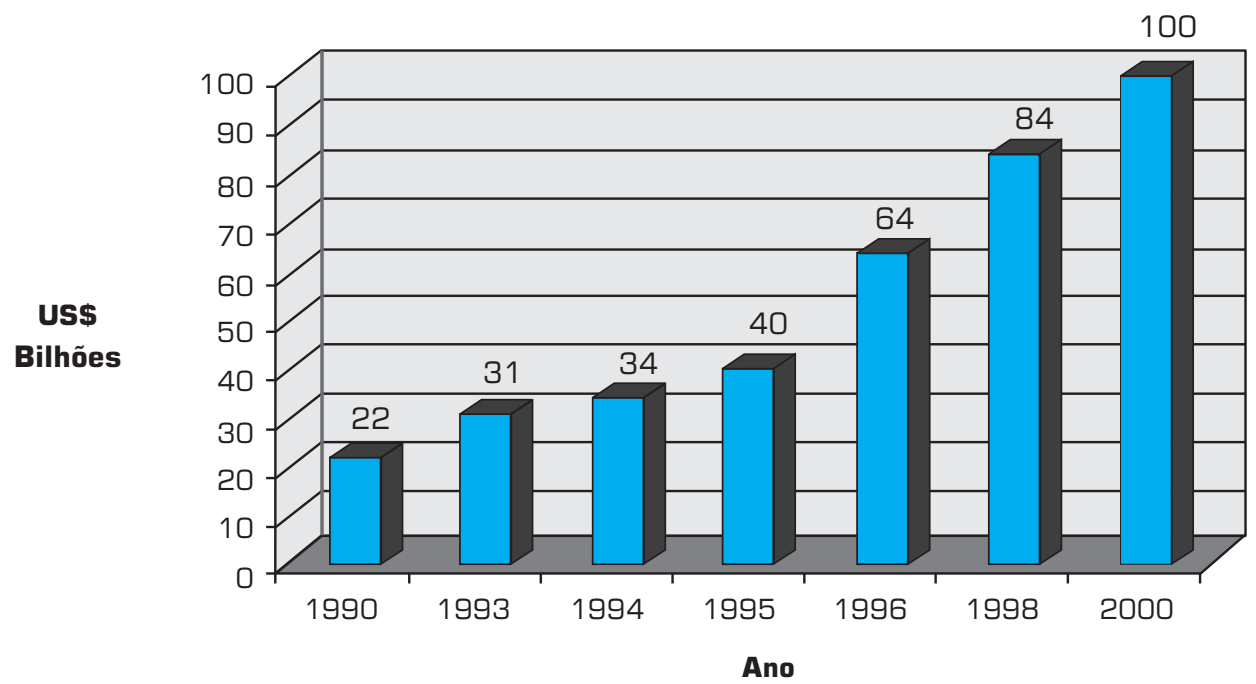

Fonte: Donadone (2002). 
como um pólo dominante no mercado mundial de consultoria, influenciando tanto pela razão de ganho de escala, proporcionado pelo porte das empresas, quanto pela abrangência de sua área de atuação. Por exemplo, em 1996, a Price contava com 400 escritórios em 118 países e Andersen, 152 escritórios em 46 países.

Outro polo tradicional do período de formação das empresas de consultoria e que aparece em destaque é o setor das empresas especializadas em Estratégia Organizacional, tendo como ícones a Mckinsey e a Booz-Allen e Hamilton. Ao analisar o período, pode-se perceber a importância delas no mercado de consultorias, por exemplo, pelo faturamento da Mckinsey de US \$ 2,9 bilhões, que a situava entre as empresas líderes do mercado mundial. A questão do crescimento do porte e das áreas de abrangência das empresas também aparece para essas empresas, como é o caso da Mackinsey, que no início da década de oitenta contava com aproximadamente 600 consultores e em 1996 apresentava um contingente de 3.900 empregados, atuando em 32 países.

Outro dado relevante é o crescimento das empresas de consultoria relacionadas à tecnologia de Informação. Numa primeira visualização com a liderança da Andersen Consulting, mas também com a movimentação de gigantes do ramo de informática por meio de diversificação dos negócios, como a IBM. Elas buscavam ocupar um espaço no mercado de consultorias, vendendo soluções que aliassem os processos de mudanças e formulações estratégicas das empresas ao suporte da Tecnologia de Informação.

Também é importante notar o crescimento do espaço ocupado pelas empresas que tinham sua origem e principal área de atuação na transformação de teorias e idéias desenvolvidas nos meios acadêmicos em pacotes gerenciais. Mais especificamente, na tabela pelo posicionamento da BCG Consulting. Desde os anos sessenta, a empresa buscava oferecer ferramentas baseadas em conceitos acerca do mundo empresarial que pudessem ser facilmente assimilados e manipulados pelas empresas, sendo emblemática, e em muitos casos confundida com a própria empresa, a sua matriz de portfolio. Nela, a BCG buscava classificar as empresas em quatro grupos, de acordo com suas capacidades de gerar receitas e ocupar parcelas de mercado. A identificação de em que grupo a empresa se encontrava fornecia uma expectativa no retorno do capital investido e dos riscos associados a este investimento. A funcionalidade e simplicidade do esquema, que cobria os mais diversos ramos industriais, servia de base para o sucesso e a difusão do mesmo, configurando-se, praticamente, como um "blue book" no qual os executivos poderiam buscar de forma automática auxílio para a tomada de decisões.
A importância da posição da BCG em relação às outras consultorias serve de indicativo do crescente espaço que essa forma de atuação ganha no mercado de consultoria e também das mudanças por que passavam essas empresas, que se caracterizavam pelo pequeno porte, contando normalmente com, no máximo, uma centena de empregados em empresas, em firmas de um considerável tamanho, como no caso da BCG, que em 1996 tinha 1.500 funcionários.

Além da maior visibilidade e de novas áreas de atuação, o crescimento das consultorias no início da década de noventa também trazia consigo questionamentos sobre eficácia e as formas de atuação dos consultores, representados principalmente pelas discussões sobre modismos e gurus gerenciais. Começam a aparecer de forma sistemática críticas à sucessão de "fórmulas salvadoras de empresas", às condutas éticas dos consultores.

Como exemplo emblemático, utilizava-se o ocorrido na AT\&T, um dos gigantes do setor de telecomunicação mundial. A empresa, a partir dos anos oitenta, tornou-se uma das principais clientes das consultorias, tendo gastado só na primeira metade dos anos oitenta mais de meio bilhão de dólares em tais serviços. Entretanto, apesar de armada de um exército de consultores e dos mais variados tipos de fórmulas de sucesso, a empresa apresentou um desempenho que passava longe do prometido pelos seus consultores, como, por exemplo, no caso da compra da NCR por valor bem acima do valor de mercado. Perante tais acontecimentos, John Walter, ao tomar posse como novo presidente em novembro de 1996, decidiu afastar todos os consultores e declarar que não eram mais bem-vindos na empresa.

As críticas, aliadas a um acirramento na concorrência, também começam a influir na forma de atuação dos consultores, sendo referência a questão de não poderem mais, como na década de oitenta, vender análises e idéias de mudanças, mas sim, conjuntamente ao diagnóstico e pacotes gerenciais, um movimento na direção de implementar as soluções propostas.

Apesar dos questionamentos, o setor continuou a apresentar um crescimento que ganhava destaque nos meios empresariais na segunda metade dos anos noventa, fechando a década com um faturamento $150 \%$ maior que em 1995 e com um crescimento de aproximadamente $354 \%$ nos anos noventa, e com abrangência mundial.

Ao fechar a cronologia do período e fornecer elementos que possam ajudar no entendimento da dinâmica do setor na passagem dos anos noventa, é possível destacar alguns aspectos que nos ajudam a entender as transformações do setor no final da década de 1990. Uma primeira questão, que é possível visualizar na comparação, é o surgimento da Accenture Consulting como maior empresa em faturamento do setor. A nova firma era o resultado 
de uma disputa jurídica entre a Arthur Andersen e a Andersen Consulting. Ao visualizar o embate, podem-se destacar dois aspectos centrais: o primeiro relacionado ao crescimento do faturamento do setor de consultoria em relação às tradicionais áreas de atuação das Accounting Firms, exemplificado pelo fato de que em 1997 pela primeira vez o setor de management consulting tinha receita maior que auditoria e impostos. De um outro lado, a disputa era balizada na idade, formação profissional e forma de atuação dos envolvidos. Do lado mais tradicional, os auditores, advogados e pessoas ligadas a aspectos de contabilidade, com uma relação fundamentada na longevidade, continuidade e sigilo das transações com os clientes. Em oposição, surgia um exército de jovens recém-saídos das Business Schools e Centros de Tecnologia armados de MBAs e habilidades em Tecnologias de Informação e com um relacionamento baseado na venda de ferramentas e pacotes-gestão.

A questão também passava por aspectos jurídicos, uma vez que começavam a ganhar evidência as discussões acerca da legalidade de operações de avaliação de empresas em processo de fusão e a implantação das mudanças pela mesma Consultoria, sendo referência o fato de a Deloitte \& Touche optar atuando no primeiro segmento em atividades que deram sua origem, como uma empresa de Accounting, e a vender o segundo segmento à Cap Gemini.

Cabe também destacar a continuidade no processo de fusão entre grandes empresas, como a junção da Pricewaterhouse com a Coopers \& Lybrand. A nova empresa nasceu como segunda maior empresa de consultoria do mundo, com um faturamento que superava os US $\$ 9,0$ bilhões de dólares e representava a concentração ainda maior tanto nas Accounting Firms, com atuação mundial, quanto nos setores das consultorias oriundas destas, que agora formavam não mais as seis grandes, mas sim as cinco grandes: Pricewaterhousecoopers, Arthur Andersen, Ernst \&Young, KPMG e Deloitte Consulting.

Outro aspecto a se destacar foi a ampliação dos portifolios de atuação das empresas. Firmas especializadas em estratégia, focadas na difusão de pacotes gerenciais e de TI, procuravam oferecer também serviços que pudessem contemplar "soluções completas", tanto suas especialidades quanto às desenvolvidas pelos concorrentes. Isso se dava por meio do desenvolvimento de setores dedicados e/ ou alianças entre empresas. Como exemplo, a CSC. A empresa foi formada a partir da fusão da CSC Consulting e da Index, e aliava o crescimento originário na difusão e implementação dos processos de reengenharia, no qual um dos fundadores da empresa, James Champy, era uma das principais referências mundiais, e a Tecnologia de Informação desenvolvida pela Index. Como resultado da fusão a empresa tornou-se quinta maior consultoria do mundo.

\section{Novos formatos das empresas, crescimento das consultorias e novo formato dos conteúdos gerenciais.}

Ao analisar a dinâmica organizacional do período numa primeira abordagem, é possível estabelecer conexões que possibilitem o entendimento do crescimento do setor de consultorias. Os processos de reorganização associados às novas configurações do controle das empresas, representados emblematicamente pelas fusões, aquisições e, em especial no caso brasileiro, a privatização, abrem um grande espaço de atuação às empresas de consultoria. Utilizam-se como suporte, tanto para a discussão da dinâmica do espaço de consultoria quanto na análise dos embates entre gerentes e consultores, dados e interpretações provenientes da cartografia inicial do espaço de consultoria brasileiro, desenvolvida no meu trabalho de doutorado (DONADONE,2003).

Para auxiliar no entendimento de como se dá a relação entre consultores e as empresas, é preciso focalizar as funções das consultorias. Como ponto de partida recorro a formulações teóricas de Coget (1999), segundo as quais a atuação dos consultores estaria concentrada em três categorias. A primeira estaria ligada ao uso dos consultores na arbitragem de disputas internas e externas às empresas, fornecendo legitimidade às ações. A segunda função dos consultores estaria relacionada à sua capacidade de produzir e difundir conceitos acerca do mundo empresarial. Como última característica, aparece o seu uso na implementação de mudanças organizacionais.

Quanto à questão da arbitragem externa, os embates entre os novos "donos" das empresas fornecem um amplo campo para a utilização das consultorias como meio legitimo de análise do desempenho financeiro das empresas. Como exemplo, tem-se a forma como é estruturada a venda de empresas estatais, na qual duas consultorias avaliam as empresas, apontam seus problemas e sugerem compradores. Nas disputas internas, torna-se comum o uso das consultorias como uma arma na disputa pela validação do desempenho de determinada unidade ou departamento perante os demais setores da empresa, principalmente com a crescente focalização dos "core process" e, por conseqüência, a venda ou desativação das áreas pouco rentáveis.

A questão da utilização do ideário oriundo das consultorias, bem como de consultores na implementação de mudanças organizacionais, vem no bojo das reestruturações. Os gerentes buscam aumentar o desempenho das suas unidades como uma tentativa de alcançar o desempenho econômico esperado. Desta maneira, buscam soluções que possam auxiliá-los neste objetivo. Cabe ressaltar que os processos de busca de legitimidade para as ações e a implementação das mudanças organizacionais estão intimamente relacionados, uma vez que a 
justificativa pela escolha em muitos casos dá suporte para sua implementação.

As transformações que estão em curso nas organizações têm fundamentos sutis, que ultrapassam as explicações fornecidas acerca dos processos de mudança mais comumente difundidos na análise organizacional. Assim, recorro a duas formulações teóricas na tentativa de aprofundar a análise do crescimento do espaço de atuação das consultorias.

Primeiramente, recorro aos conceitos de Orlean sobre como se dá o poder da lógica financeira. Suas formulações enfatizam que o ponto central da lógica financeira, a liquidez dos investimentos, está baseado num sistema de opiniões suportado por um mecanismo cognitivo, ou seja, as expectativas de lucro sobre determinados investimentos depende de uma série de avaliações que se auto referenciam e que têm sentido somente a partir de tal ponto de vista.

Tal construção teórica traz contribuições importantes a este trabalho. Primeiramente pelas questões relacionadas à necessidade da transparência das codificações das informações econômicas como instrumentos essenciais do poder e de influência da lógica financeira nas empresas, ou seja a capacidade de avaliar o desempenho das empresas e arbitrar entre eles. Neste sentido, vale relembrar que a formação e desenvolvimento do setor de consultorias em muito foi fundamentado nos relatórios sobre a saúde financeira das empresas, como nos emblemáticos Survey's Bank. A questão também nos remete aos conteúdos teóricos formulados por Fligstein (1990) sobre o processo de construção da lógica financeira,ou seja, as empresas recorriam à análise financeira como forma de acompanhar e avaliar o desempenho das aquisições em setores com os quais tinham pouca familiaridade. Característica, também, presente e intrínseca dos investidores institucionais.

Como outro suporte para a análise aqui desenvolvida recorro aos trabalhos de Douglas, em especial nas sua formulações acerca dos sistemas de classificação cultural por meio dos quais os agentes dão sentido e formato a suas ações.

Como discutido por Useem (1993), com o crescimento da influência dos investidores institucionais há uma mudança nos conteúdos atribuídos aos gerentes dos diversos níveis da empresa. O formato de gerente que baseava sua atuação no cumprimento rigoroso das tarefas e visualizava a carreira como uma série de posições a serem ocupados nos diversos níveis hierárquicos começa a ser questionado. A forma de poder resultante da hierarquização burocrática começava a sofrer sérios danos. Com a demissão de parcelas consideráveis da gerência média, a necessidade de pensar a empresa em termos financeiros e a curto prazo, começa a ruir o esquema de distribuição de poder formado ao longo das última décadas de revolução gerencial.

$\mathrm{Na}$ literatura gerencial do período aparecem uma série de obras que chamam a atenção para o processo de perda de poder dos gerentes e a transformação do seu relacionamento com a empresa em bases somente financeiras, como por exemplo: A corrosão do caráter: conseqüências pessoais do trabalho no novo capitalismo; Le manager jetable; e L'entreprise barbare. Ao analisar os conteúdos dos trabalhos gerenciais divulgados pela revista Exame, no decorrer da década, encontram-se por exemplo: i) quanto à relação centrada em aspectos financeiros com empresas: $\mathrm{O}$ executivo é o próprio negócio; Seja seu próprio Head Hunter; e Negociar em causa própria não é feio; ii) já quanto às representações das estruturas organizacionais: Não se fazem mais pirâmides como antes; A Hierarquia treme e Somem cadeiras no Olimpo; ou como síntese das duas temáticas: Prepare-se. Vem aí o executivo ocasional.

Ao visualizamos esta questão a partir das formulações de Douglas (1996), é possível tecer considerações que vêm nos ajudar a entender as mudanças. Parece que é possível visualizar um processo de guerra cultural onde a visão financeira da empresa se encontra situada no quadrante do Individualismo ativo. Onde seus representantes buscam a maximização dos seus investimentos no curto prazo e por meio desta desenham o controle das organizações.

No outro pólo encontram-se os gerentes com suas expectativas desenvolvidas de acordo com um esquema cognitivo formado na burocracia, ou seja, de uma forte hierarquização. O formato do embate ganha importância para o esquema explicativo deste trabalho, uma vez que, ao entrevistar-se os consultores, um ponto comum dos entendimentos era a sua distinção em relação ao mundo gerencial, apresentado quase sempre como burocrata ou

Quadro 2: As formas de atuação dos consultores nos processos de mudanças organizacionais.

\begin{tabular}{|l|l|}
\hline Arbitragem externa & $\begin{array}{l}\text { - Avaliar as empresas, apontar seus problemas e sugerir compradores nos processos de } \\
\text { fusões e privatizações } \\
\text { - Validar o desempenho de determinada unidade ou departamento }\end{array}$ \\
\hline $\begin{array}{l}\text { Difundir/gerar } \\
\text { conceitos gerenciais }\end{array}$ & $\begin{array}{l}\text { - Crescente literatura/gurus sobre como gerenciar as empresas } \\
\text { - Busca pelos gerentes de legitimidade e referência perante as mudanças na empresa }\end{array}$ \\
\hline Atuação nas empresas & - Redesenhos organizacionais, a partir do "core business": reengenharia e downsizing \\
\hline
\end{tabular}


"que criava barriga na mesma empresa". Cabe ressaltar que os processos de hierarquização e classificação próprios da estruturação do campo, davam-se não apenas em embates discursivos mas também eram internalizados nas organizações, sendo representativo o formato matricial de trabalho das grandes consultorias, ou os 'projetos' das consultorias acadêmicas, frente à sempre mencionada pirâmide organizacional das empresas.

Outra questão que merece destaque para entender o embate é a forma de ascensão na carreira de consultor nas grandes empresas de consultoria. Como central aparecem as idéias associadas ao Up or Out, ou seja, a combinação de um forte afunilamento nas possibilidades de promoção aliado a uma prática de demissão ou quase exclusão voluntária dos que passassem de um determinado período nas empresas, normalmente de três a cinco anos. Tal mecanismo e as formas de socialização associadas a ele produziam um repertório de entendimentos sobre os possíveis arranjos organizacionais que vinha de encontro às formas de promoção e carreira das empresas industriais, normalmente estruturadas a partir de diversos níveis gerenciais oriundos na forma de distribuição do poder por meio de uma forte hierarquização. O interessante é que a polarização se dava, ainda que com contornos e grau de sofisticação do argumento diferentes, também entre os consultores individuais, como por exemplo em construções do tipo: "agora não dependo de ninguém para subir" ou "as empresa deveriam dar trabalho, não emprego às pessoas" (DONADONE,2003).

Dois aspectos merecem destaque. O primeiro relacio- nado ao formato dos embates entre consultores e gerentes, que eram direcionados pelo posicionamento nos respectivos campos, ou seja, há uma mitigação na diferenciação entre consultores e gerentes em posições homólogas. Como emblemático na relação entre as formulações dos consultores da Mckinsey e seus clientes, em número considerável, diretores de grandes empresas e egressos da mesma. O segundo remete ao processo de violência simbólica,como discutido por Bourdieu (2000), no qual os embates passam quase que a não ser mais mencionados e há uma naturalização da posição dominante, exemplificado no fato de os gerentes visualizarem na atuação dos consultores o modelo de conduta a ser seguido perante um "mundo que privilegia o curto prazo e a capacidade de se vender todo dia".

$\mathrm{O}$ último tópico traz consigo formulações que são fonte de novas pesquisas, em processo de investigação por parte dos autores deste texto, que contemplam os conteúdos gerenciais surgidos a partir das novas configurações nas empresas e as formas de inter-relacionamento entre consultores e gerentes. Especificamente no campo da engenharia, e mais diretamente na engenharia de produção, pela sua forte ligação com a difusão e implantação de modelos de gestão (ZILBOVICIUS, 1999), os estudos relacionados às formas de atuação, desenvolvimento das carreiras e conteúdos atribuídos ao engenheiro de produção frente a um horizonte organizacional onde, segundo pesquisa (CATHO/IBCO,2003), os engenheiros representam a maior parcela $(29,12 \%)$ entre os consultores independentes atuantes no mercado brasileiro.

\section{Artigo recebido em 12/03/2003 Aprovado para publicação em 04/08/2004}

\section{- Bibliografia}

BOURDIEU, Pierre. Les structures sociales de l'économie.Paris:Éditions du Seuil, maio 2000.

CHANDLER Jr, A. D.: The emergence of managerial capitalism. In: ZUKIN, A.

COGET, Xavier. Les Cabinetes de Conseil en management: origines et Funciones. Paris, Septembre de 1999, 146 pág. Tese de doutorado da EHESS-França.

DIMAGGIO, P. J. Structures of capital: the social oganization of the economy. Cambridge University Press, 1990.

COMIM, A. O crescimento das fusões e aquisições no Brasil e no mundo: uma avaliação das tendências recentes. $L E P$, Campinas , (3): 63-87,dezembro de 1996.
DONADONE, J.C. "Os hunos já chegaram": Dinâmica organizacional, difusão de conceitos gerenciais e a atuação das consultorias. Tese (Doutorado) - Escola Politécnica da Universidade de São Paulo. Departamento de Engenharia de Produção. Março 2002.

DOUGLAS, Mary. Thought Styles. Critical essays on good taste. London, Sage 1996.

FLIGSTEIN, N., MARKOWITZ, L. The finance Conception of the corporation and the causes of de finance reorganization of large Corporation, 1979-1988. In: Sociology and Social policy, edited by W. J. Wilson. Beverly Hills, EUA. Sage.

HENRY, Odile. Entre savoir et povoir. Actes de la Recherche en Sciences Sociales, n. 95, p. 37-54. Paris. Decembre 1992.
MELLO Jr., Luiz R. Privatização e governança empresarial no Brasil. In: PINHEIRO, Armando Castelar, FUKASAKU, Kiichiro (ED.). A Privatização no Brasil. O caso dos serviços de utilidade pública. 1. ed. Rio de Janeiro: BNDES, 2000

MCKENNA,. The origins of modern Management Consulting. Business and Economic History, volume 24, nro 1, fall 1995

ORLEAN, André. Le pouvoir de la finance. Paris. Editions Odile Jacob, outubro de 1999.

PINHEIRO, Armando Castelar. Privatização no Brasil: Por quê? Até onde? Até quando? In: GIAMBIAGI, Fábio, MOREIRA Maurício Mesquita. Organizadores. A economia brasileira nos anos 90. 1. ed. Rio de Janeiro: BNDES, 1999.
SIFFERT FILHO, Nelson, SOUZA e SILVA, Carla. As grandes empresa nos anos 90: respostas estratégicas a um cenário de mudanças. In: GIAMBIAGI, Fábio.

MOREIRA Maurício Mesquita Organizadores. A economia brasileira nos anos 90. 1. ed. Rio de Janeiro: BNDES, 1999.

USEEM, Michael. Investor capitalism: how money mangers are changing the face of corporate America, New York, Basic books, 1999.

Executive defense. Shareholder $\overline{\text { power }}$ and corporate reorganization. Cambridge, Massachusetts, Harvard University Press, 1993.

ZILBOVICIUS, Mauro. Modelos de produção, produção de Modelos: gênese, lógica e difusão do modelo japonês. São Paulo: FAPESP: Annablume, 1999. 